NASA Technical Memorandum 105433

$1 N-20$

AIAA-92-1185

\title{
68748
}

$6^{21}$

\section{Design Issues for Lunar In Situ Aluminum/Oxygen Propellant Rocket Engines}

Michael L. Meyer

Lewis Research Center

Cleveland, Ohio

Prepared for the 1992 Aerospace Design Conference

sponsored by the American Institute of Aeronautics and Astronautics Irvine, California, February 3-6, 1992

\section{N/SN}

(NASA-T4-105433) DFSTON ISSUES FOR LUNAR IN

N92- 16023

SITU ALUMINUM/UXYGEN PROPFLLANT ROCKET

ENGINES (NASA) $21 p$

CSCL $21 \mathrm{H}$ 


\title{
DESIGN ISSUES FOR LUNAR IN SITU ALUMINUM/OXYGEN PROPELLANT ROCKET ENGINES
}

\author{
Michael L. Meyer \\ National Aeronautics and Space Administration \\ Lewis Research Center \\ Cleveland, Ohio 44135
}

\begin{abstract}
Design issues for lunar ascent/descent rocket engines fueled by aluminum/oxygen propellant produced in situ at the lunar surface were evaluated. Key issues are discussed which impact the design of these rockets: aluminum combustion, throat erosion, and thrust chamber cooling. Four engine concepts are presented, and the impact of combustion performance, throat erosion and thrust chamber cooling on overall engine design are discussed. The advantages and disadvantages of each engine concept are presented.
\end{abstract}

\section{Introduction}

Utilization of rocket propellants produced in situ from extraterrestrial resources is an approach which may lower the cost of future space exploration missions by substantially reducing the mass of propellant that must be launched from Earth. Lunar soil, which is primarily composed of metal oxides, is the nearest abundant source of extraterrestrial material available for in situ rocket propellant production. An average elemental breakdown of the lunar soil is shown in Table 1.1 The lunar oxides may be chemically processed to produce propellant grade oxygen, the use of which could significantly reduce oxidizer supply requirements for lunar ascent/descent vehicles. In addition, aluminum, magnesium, and silicon are elements which may be processed from lunar soil in significant quantities and have high heats of combustion with oxygen. These elements could perform well as rocket fuels. $^{2,3}$ Aluminum is abundant in the lunar soil (locally available in concentrations up to $14 \%$ by weight) and, with oxygen, has the highest density impulse of in situ propellant combinations derived from lunar soil, as shown in Table 2.

Producing propellant from the lunar soil requires mining, beneficiating, and processing the ore and storing the final product. Equipment and energy will be needed for in situ production, and after the production system is put in place, worn parts may require replacement and the reagents used during chemical processing of the ore must be resupplied. With currently available production technology, the necessary supply of parts and chemicals to maintain an aluminum/oxygen plant is predicted to be $3-5 \%$ of the mass of propellants produced. ${ }^{4}$ Furthermore, because aluminum/oxygen has a considerably lower specific impulse than hydrogen/oxygen, more propellant is consumed per pound of thrust generated by the rocket. Performance losses, which may reduce specific impulse, will increase 
propellant production and resupply requirements. Therefore, to minimize the supply line from Earth and to maximize the benefits of using an in situ propellant, it is important to consider engine design issues for optimum performance and reliable, maintenance-free operation of lunar ascent/descent propulsion systems fueled by in situ propellants.

Propulsion concepts for a lunar ascent/descent vehicle supporting a manned lunar base were considered in this study. The vehicle is capable of delivering a $6800 \mathrm{~kg}$ crew capsule in addition to $10,400 \mathrm{~kg}$ of payload between the lunar surface base and low lunar orbit. On the surface, the vehicle is loaded with in situ propellant for a round trip. It then ascends to rendezvous with a lunar transfer vehicle in low lunar orbit, transfers payload and crew, and returns to the surface. Maintenance operations on the propulsion system are assumed to be done, either by crew or by robot, while on the lunar surface before the vehicle is loaded for the next trip. Analyses of this type of mission indicate that two to five $66,700 \mathrm{~N}$ thrust engines would be sufficient to propel a wide range of lunar ascent/descent missions, piloted

and un-piloted. 2,3 Further, an engine burn time of 360 seconds per mission provides the necessary total impulse for the mission. ${ }^{3}$ Engine throttling will be necessary, and engine-out capabilities are desirable.

Issues which impact the design of an aluminum/oxygen engine for a lunar ascent/descent vehicle are discussed in this paper, which includes the results of previous studies which considered design issues for aluminum/oxygen rocket engines. These issues include performance losses associated with aluminum fuel, throat erosion, and thrust chamber cooling. To better understand the significance of the issues, four engine concepts, each using a different method of supplying the metal fuel to the combustion chamber, and the impacts of the design issues on each concept, are considered.

\section{Engine Concepts}

Four engine concepts fueled by lunar aluminum/oxygen in situ propellant which were considered in this analysis are shown in figures 1-4. These concepts are based on similar concepts originally proposed in references $2,3,5$, and 6 . The concepts differ in the method the propellant is stored and delivered to the combustion chamber.

In the concept shown in figure 1 , the metal fuel is liquified prior to injection into the combustion chamber. Liquefaction of the metal fuel enables use of more conventional liquid propellant feed system designs. The energy required to liquify the metal fuel could be provided by an on-board supply, beamed energy, or heat transmission from the combustion chamber. A positive expulsion system would force the metal pellets into the heat exchanger where they are liquefied. As an alternative to liquefaction of the fuel on board, the metal fuel could be liquified prior to loading it into insulated vehicle tanks and stored as a liquid.

A hybrid engine concept in which liquid oxygen is injected into a thrust chamber containing a solid aluminum grain is shown in figure 2. Autogenous pressurization is used for the oxygen. A liquid oxygen pump, with a gaseous oxygen-driven turbine, could also be 
used to pressurize the LOX. A classical hybrid, as depicted in figure 2, was considered by Sparks ${ }^{5}$. More recently, a variation of the aluminum/oxygen hybrid was studied conceptually by Brower et al. ${ }^{6}$ The latter design consisted of bundled aluminum rods with oxygen flowing axially between the rods. As the oxygen flowed along the rods, it acted both as a coolant for the length of the rods and as the oxidizer when it reached the end of the rods. In this manner, the engine would operate as an end burner. However, balancing the cooling, to prevent conduction of the heat from combustion into the gaps between the rods and early melting of the rods, was not resolved.

A third concept utilizes monopropellant aluminum/oxygen. The monopropellant is formulated by suspending powdered metal in liquid oxygen. Two recent studies have tested the feasibility of producing and handling a metal/LOX monopropellant. ${ }^{7-9}$ When a gellant is added, the mixture can be stored and handled much like a non-newtonian liquid propellant. Figure 3 is a sketch of this concept. An inert gas or a slurry pump would be used for pressurization. Though an inert gas pressurant would probably have to be supplied from Earth, it would be preferable to gaseous oxygen (GOX) pressurization because GOX could cause auto-ignition of the metal fuel.

The last aluminum/oxygen engine concept presented uses pneumatic transport and injection of powdered metal fuel. As shown in figure 4, powdered aluminum would be placed in a storage and entrainment tank. From the tank, the powder is delivered to a flowing stream of pressurant/carrier gas which transports the fuel to the combustion chamber. Using a low molecular weight carrier gas, even in amounts less than a few percent by weight of the fuel, significantly improves specific impulse performance of aluminum/oxygen propellant. ${ }^{3,10}$ The performance improvement is due to a reduction of the exhaust product molecular weight. Thus, the penalty of carrying a small amount of pressurant from earth may be off-set by the large specific impulse improvement. Oxygen would be injected into the combustion chamber separately, and the propellant would mix there and burn. Some experience with this type of system was obtained in past studies using pneumatic transport of powdered metals as a method of obtaining a more dense missile fuel. ${ }^{11,12}$

\section{Design Issues}

Several issues must be addressed to design an aluminum/oxygen engine. Based on experience with solid propellant rockets employing metal additives, the most challenging issues for aluminum/oxygen rockets are aluminum combustion, throat erosion, and thrust chamber cooling.

\section{Aluminum Combustion}

Two important performance loss phenomena due to aluminum combustion have been identified from work with solid propellants: two-phase flow losses and incomplete metal combustion. When aluminum is burned in a rocket engine, a fraction of the exhaust will be 
in condensed phases such as liquid aluminum and liquid or solid oxides of aluminum. The majority of the condensed material will be aluminum oxide, $\mathrm{Al}_{2} \mathrm{O}_{3}$. If the condensed phase particles are sufficiently large, they will no longer maintain velocity and thermal equilibrium with the gaseous exhaust products. This state of non-equilibrium results in a performance degradation. When condensed particles lag in velocity, the momentum of their fraction of exhaust mass is lower than would be ideally achieved. If the condensed material does not maintain thermal equilibrium, the thermal energy stored in the particle is not fully converted to kinetic energy. The velocity lag typically causes a greater reduction in performance than thermal lag. ${ }^{13}$

The thrust performance loss due to the velocity lag of the condensed phase exhaust material can be estimated by subtracting the difference between the actual momentum of the condensed material and the momentum it would have without velocity lag from the total predicted exhaust momentum. Following the procedure of Sarner ${ }^{14}$, the impact of this momentum loss on specific impulse can be estimated. Ideal vacuum specific impulse can be defined as $I_{v a c}=u / g_{o}$, where $u$ is the bulk velocity of the exhaust, and $g_{o}$ is the gravitational acceleration of the Earth. For an engine with condensed phase material of mass fraction $m_{p}$, the exhaust momentum can be broken down into that of the gaseous material and that of the condensed material. The specific impulse accounting for velocity lag, $\mathrm{I}_{\mathrm{VL}}$, is then

$$
I_{V L}=\frac{m_{p} u_{p}+m_{g} u_{g}}{g_{o}}
$$

The subscripts $g$ and $p$ represent the gaseous and particulate fractions of the exhaust. Since $\mathrm{m}_{\mathrm{p}}+\mathrm{m}_{\mathrm{g}}=1$, if equation (1) is divided by the ideal specific impulse, we can obtain

$$
\frac{I_{V L}}{I_{V A C}}=1-\left(\frac{u_{g}-u_{p}}{u_{g}}\right) m_{p}
$$

for the relative specific impulse including velocity lag. This ratio is the velocity lag efficiency of the engine. The coefficient of $m_{p}$ is the particle relative velocity lag.

A parametric study was carried out to evaluate the impact of velocity lag on specific impulse of an aluminum/oxygen propellant engine. Values of particle relative velocity lag of 5,10 , and $15 \%$ were applied to results for specific impulse and condensed phase mass fraction obtained from chemical equilibrium calculations. ${ }^{15}$ The effect on specific impulse is shown in figure 2 as a function of oxidizer to fuel mixture ratio. This figure illustrates the difference between the ideal specific impulse and the velocity lag reduced specific impulse, reflecting efficiencies as low as $90 \%$. In addition, the mixture ratio for maximum specific impulse shifts to higher values as the particle relative velocity lag increases. The shift is due to a reduction in the mass fraction of condensed phase exhaust material (and hence two-phase losses) as mixture ratio is increased from 2.3. 
The relative velocity lag of the preceding analysis depends on the sizes of particles formed in the exhaust. If the particles formed are small enough, they will remain in velocity equilibrium with the gas flow. Particles below $1 \mu \mathrm{m}$ follow the gas closely, so the two-phase flow losses associated with them is small. Between 1 and $10 \mu \mathrm{m}$, the velocity lag losses increase with increasing particle size, but as particle sizes increase above $10 \mu \mathrm{m}$, the increase in two-phase flow losses diminishes. Therefore, reductions in particle sizes below $10 \mu \mathrm{m}$ will reduce the velocity lag losses, and if particle sizes are forced below $1 \mu \mathrm{m}$, the velocity lag losses will be minimal. ${ }^{14}$

Consideration of the mechanisms by which particulates form in aluminized solid propellant motors may provide the necessary insight to minimize exhaust particle size in aluminum/oxygen rocket engines. Two mechanisms are generally accepted as aluminum combustion methods by which particulates form and grow in solid propellant rocket engines. ${ }^{16-19}$ The first is by nucleation from exhaust gases and agglomeration. Small particles are formed as exhaust gases condense. These particles collide and form larger particles. The second method of formation, droplet surface combustion, is believed to cause most of the larger particles. Droplets of aluminum bleed to the surface of the solid propellant grain and coalesce to form larger drops. When these drops of metal approach 100 $\mu \mathrm{m}$ to $200 \mu \mathrm{m}$ in diameter, the drag force on them is strong enough to lift them from the surface into the combustion zone. Aluminum combustion occurs at the surface of the drop. Then the aluminum oxide condenses back onto the drop surface and forms a shell which can impede or extinguish combustion until thermal expansion of the aluminum core cracks the shell. In this manner an oxide particle is formed of comparable size to the original fuel drop. These larger $\mathrm{Al}_{2} \mathrm{O}_{3}$ particles lag significantly in velocity, while the smaller particles, which are moving quickly, collide and agglomerate. In the throat region, high acceleration causes strong sheer forces which can rip the large particles apart. At the same time, the flow area has decreased and velocity differences between large and small particles is increased. These two effects cause more collisions and agglomeration. The combination of the factors typically results in a bimodal distribution of exhaust particle sizes with peaks at 2 $\mu \mathrm{m}$ and approximately $50 \mu \mathrm{m} .{ }^{16}$ The particles in the $50 \mu \mathrm{m}$ peak, formed by surface combustion of large aluminum drops, cause most of the two-phase flow losses incurred. Therefore, it would be beneficial to shift the $50 \mu \mathrm{m}$ peak to a smaller particle size or to reduce the number of particles in that size range.

The surface combustion of aluminum fuel may also lead to another loss, combustion inefficiency. If an oxide shell forms on the fuel drop surface, the combustion rate may be slowed. Collection of exhaust products from solid propellant rocket engines has found that some unburned aluminum is expelled from the engine. ${ }^{18}$ The resulting incomplete release of energy from the reactants causes a reduction in performance. The reason for the incomplete energy release is insufficient residence time for mixing, ignition, and combustion in the chamber. The required times for ignition and combustion decrease with increasing reactant temperature, increasing reactant pressure, and decreasing initial fuel drop size. Both the time required for mixing and the fuel drop size are controlled by the injection system, which depends on the engine concept selected. 
By understanding the mechanisms of condensed phase product formation it may be possible to reduce the fraction of exhaust material which is in the larger size group and at the same time improve combustion efficiency. Alloying the aluminum fuel with another metal that burns in the vapor phase rather than at the drop surface may prevent the surface oxide build-up that creates larger oxide particles and slows combustion. Previous work has shown that alloys of aluminum with as little as $20 \%$ magnesium burn similarly to pure magnesium. ${ }^{20}$ Magnesium, although not as energetic as aluminum, has desirable combustion behavior. Magnesium ignites more readily than aluminum, may burn in the vapor phase, and its oxide (if it does form a shell on the drop) is much more porous than $\mathrm{Al}_{2} \mathrm{O}_{3}$. Further, aluminum/magnesium alloys burn disruptively. ${ }^{20}$ The burning drop explodes into smaller fuel droplets which should lead to smaller exhaust particles.

An alternative to using an alloy fuel would be to create smaller initial fuel droplets in an aluminum/oxygen propellant engine than are produced in solid propellant engines. Some of the engine concepts have the capability to force smaller droplet formation than occur in a solid propellant motor. If either alloy fuels or small droplet formation techniques are utilized, the velocity lag and combustion losses can be reduced.

\section{Erosion}

Solid propellant rockets suffer from erosion of their interior surfaces, which are susceptible to both chemical and mechanical erosion. ${ }^{21}$ Because, like a solid propellant motor, an aluminum/oxygen engine will have a large fraction of condensed material and an oxygen rich environment, it will be vulnerable to erosion as well. In solid propellant motors, the erosion problem is often handled by using sacrificial throat inserts which ablate during the burn. By using an ablative insert, both the throat erosion and the throat cooling are controlled. It may be feasible to use the same technology for an aluminum/oxygen ascent/descent vehicle engine, if the insert ablative thickness and mass are reasonable, and if insert burn-through, asymmetric erosion, insert replacement, and throat size variation problems can be resolved.

The mass and thickness of a throat insert was estimated for a representative aluminum/oxygen lunar ascent/descent vehicle engine. A thrust level of $66,700 \mathrm{~N}$ was selected based on references 2 and 3 , and a relatively low chamber pressure, $2.07 \mathrm{X} 10^{6} \mathrm{~N} / \mathrm{m}^{2}$, was assumed to avoid a requirement of pumping the metal fuel. (Metal pumping is not a consideration for a hybrid engine). For a mixture ratio of 3.0, a chemical equilibrium computer code ${ }^{15}$ was used to calculate the pressure, temperature, and chemical composition of the combustion products at the throat. Based on this information, the radial erosion rate at the throat was determined to be $75-125 \mu \mathrm{m} / \mathrm{s}$ for a carbon-carbon material with a density of $1.9 \mathrm{~g} / \mathrm{cm}^{3}$. The range in erosion rate is a function of the exact throat geometry. Other

\footnotetext{
- Personal communication with Mr. Perry S. Bruno, Refractory Technology Aerospace Components, Magna, Utah, October, 1991.
} 
factors, of interest for performance reasons, can also affect the throat erosion rate. These factors include the size of the exhaust particulates, the chamber pressure, and the mixture ratio. For example, operating at a higher mixture ratio would increase the of oxygen available to react with the carbon insert. Thus, the erosion rate, due to chemical effects, would increase.

A burn time of 180 seconds is required for each leg of a two-leg ascent/descent mission. Thus, the throat must withstand 360 seconds of operation before being replaced. For an average erosion rate of $100 \mu \mathrm{m} / \mathrm{s}$, an erodible throat thickness of $3.6 \mathrm{~cm}$ is needed. An additional $2.5 \mathrm{~cm}$ wall thickness must remain at the completion of the burn to maintain structural integrity of the throat. This information was used to estimate the mass of a simplified conical-entrance conical-exit throat insert. The mass of the insert, $23.5 \mathrm{Kg}$, is $0.5 \%$ of the propellant mass used in a representative ascent/descent vehicle. This can be compared with estimates for propellant production reagent resupply requirement of 3-5\% of the propellant produced. ${ }^{4}$ While it has been shown that the mass of the inserts is not a large factor, further mission analysis is needed to determine whether the thrust reduction caused by the increasing throat diameter severely impacts the mission, or whether the propellant flowrate must be increased to maintain thrust at the expense of additional propellant usage.

\section{Engine Cooling}

Engine cooling is another design issue that is often raised for aluminum/oxygen engines. The significance of this issue is magnified because the large amount of particulates in the chamber will add a radiative component of heat flux to the chamber walls. It has been proposed that LOX could be used to regeneratively cool thrust chamber walls for (nonhybrid) aluminum/oxygen engines. LOX cooling is not a new concept. Much research has been conducted in this area for hydrocarbon fueled engines (references 22-25). This work successfully demonstrated LOX cooling in engines with moderate chamber pressures.

A simple, one-dimensional, heat-transfer analysis was conducted to determine if LOX cooling is feasible for an aluminum/oxygen engine. It was assumed that all of the oxygen consumed by the engine would be available for cooling purposes. This assumption eliminates the slurry monopropellant engine concept from the analysis. If sufficient cooling were provided by only a fraction of the oxygen consumed by the engine, a heavily metalloaded monopropellant could be used as the primary propellant, and additional oxygen used for cooling could be separately injected to obtain the proper mixture ratio.

A simple cylindrical thrust chamber, $25 \mathrm{~cm}$ long and $31 \mathrm{~cm}$ in diameter, was analyzed. Only the heat flux to the chamber walls was considered; it was assumed that an ablative throat insert would be used. The first step of the analysis was to determine the heat flux from the combustion products to the walls. As mentioned above, this is composed of both convective and radiative components. The convective heat flux is 


$$
q_{c}=h_{g}\left(T_{g}-T_{w}\right)
$$

where $h_{g}$ is the convective heat transfer coefficient of the hot chamber products, and $T_{g}$ and $\mathrm{T}_{\mathrm{w}}$ are the adiabatic flame temperature and hot gas side wall temperatures respectively. Because empirical heat transfer data does not exist for this propellant, the Colburn equation for the Nusselt number in pipe flow was used to determine the convective heat transfer coefficient. The thermodynamic properties of the combustion products were obtained from equilibrium calculations ${ }^{15}$ for aluminum/oxygen at a mixture ratio of 3.0 and a chamber pressure of $2.07 \times 10^{6} \mathrm{~N} / \mathrm{m}^{2}$. These operating conditions were used to remain consistent with the throat erosion analysis. To remain at a safe temperature for copper, the wall temperature was assumed to be held to $811 \mathrm{~K}$. The calculations predict a convective heat flux to the chamber wall of $1.58 \times 10^{7} \mathrm{~W} / \mathrm{m}^{2}$.

By treating the chamber products as a cloud of grey particles, the radiative heat flux to the wall was calculated. The cloud emissivity, $\epsilon_{\mathrm{CL}}$, calculated by the methods given in reference 26 and assuming an average particle size of $50 \mu \mathrm{m}$, was determined to be 0.54 . The radiative flux emitted from the combustion products is then

$$
q_{r_{C L}}=\varepsilon_{C L} \sigma T_{C L}{ }^{4}
$$

where $\sigma$ is the Stephan-Boltzman constant, $5.6703 \times 10^{-8} \mathrm{~W} / \mathrm{m}^{2}-\mathrm{K}^{4}$, and $\mathrm{T}_{\mathrm{CL}}=\mathrm{T}_{\mathrm{g}}$. The copper wall, however, will not absorb all of this radiation. In fact, because the high temperature of the chamber products shifts the spectral peak of the emitted radiation to a small wavelength, the absorptivity of the relatively cool wall is quite low, $0.19 .{ }^{26}$ The net radiative transfer involves radiation from the combustion products to the walls and radiation reflected from the opposite wall through the combustion products with some absorption. Because the wall temperature is relatively low, radiation emitted from the wall is negligible. Reference 26 provides a method to calculate the net radiative transfer in an enclosure. This method was used to calculate an effective emissivity for the combustion products. The effective emissivity is 0.164 , and the net radiative heat flux to the wall is therefore

$$
q_{r_{w}}=\varepsilon_{e f f} \sigma T_{c L}{ }^{4}
$$

The radiative heat flux calculated by this equation for the engine is $2.8 \times 10^{6} \mathrm{~W} / \mathrm{m}^{2}$ or approximately $15 \%$ of the total heat flux.

The next step of the analysis was to determine if the LOX available for cooling (i.e. all of the oxygen burned in the engine) could absorb the total chamber heat flux without undergoing an excessive temperature rise. To determine this, the total chamber heat rate was calculated, integrating the sum of the convective and radiative heat fluxes over the entire chamber wall. From this integration, the total heat rate to the chamber wall was determined to be $4.5 \times 10^{6}$ watts. The total mass flow of oxygen, which must absorb this heat rate, is $17.1 \mathrm{~kg} / \mathrm{s}$. As a liquid, this flow rate has the capacity to absorb $3.04 \times 10^{4} \mathrm{~W} / \mathrm{K}$. This 
implies that the oxygen would experience a bulk temperature increase of $148 \mathrm{~K}$. Because the thermal conductivity of LOX is much lower than that of conventional coolants, high coolant velocities and small coolant channel cross sections would be needed to transfer the heat from the channels to the cooling liquid. Obtaining the high velocities would require a large pressure drop through the channels. Further, the temperature increase would cause low pressure oxygen to pass through its liquid to vapor transition. Therefore, to avoid the complexity and uncertainty of a two-phase coolant, moderate coolant pressures $\left(\sim 5.17 \times 10^{7}\right.$ $\left.\mathrm{N} / \mathrm{m}^{2}\right)^{27}$ would be required to insure that the LOX remained liquid. For the pressure fed system considered, such pressures would not be acceptable. Hence, a pump-fed oxygen system would be necessary.

\section{Discussion}

The four engine concepts are compared in table 3. This comparison is qualitative and was not used to rank the four concepts. However, the comparison is useful for determining areas where technological or design advancements would be beneficial. All of the concepts would benefit from further development of the ablative insert concept for throat cooling and erosion protection. Only the hybrid concept needs advancement to be able to use either the alloy fuel or small fuel droplet formation techniques for specific impulse performance improvement.

\section{Liquid Metal Injection Engine}

The liquid metal injection engine concept has several advantages. One advantage is that using an aluminum/magnesium alloy, as suggested for improved specific impulse performance, is actually beneficial to the feed system. The alloy melts at a lower temperature (up to $211 \mathrm{~K}$ lower at the eutectic combination ${ }^{28}$ ) than pure aluminum, and hence, the high temperature requirements for feed system components is reduced. Another advantage of injecting liquid metal, which can also improve specific impulse performance, is that the injector can atomize the fuel into smaller droplets than are formed in a solid propellant motor. This concept can also readily accept inserts to handle throat cooling and erosion, and although the chamber cooling analysis indicated a pump fed system is necessary for engine cooling, all of the oxygen is available for cooling. Thus, high pressure oxygen could cool the chamber. However, pumping the liquid metal fuel would be a challenge.

One disadvantage of the liquid metal fuel engine concept is that the metal fuel may solidify and clog feed lines. Purging the lines to expel fuel at shutdown may be possible, but the complexity and mass of the purge system would have to be considered. Another disadvantage of this system would be maintenance requirements. The throat inserts considered must be replaced after each mission, and the insert assembly must be cleaned and inspected before the new insert is installed. In addition to the throat insert maintenance, the high temperature feed system components would require inspection to determine wear and replacement if damaged. The wear on the high temperature components can also be considered a safety issue. Perhaps the greatest disadvantage of the liquid metal engine 
concept is the energy required to melt and maintain the metal fuel in a liquid phase. An on board energy supply to melt the fuel would be too massive to be practical, and other options (beamed energy, heat transmission from the chamber, pre-flight liquefaction) have technology issues of their own.

\section{Hybrid Engine}

Of the engine concepts considered, the simplest is the hybrid. In fact, simplicity is its greatest advantage. Only one propellant feed system is needed, for liquid oxygen. Inherent with this simplicity is safety. In addition to safety, another advantage is that the thrust of a hybrid engine can be controlled by increasing or decreasing the oxygen flowrate to the engine, and shut-down can be accomplished by stopping the oxygen flow.

Several disadvantages are also inherent in the hybrid aluminum/oxygen engine concept. The primary problem is maintaining controlled metal regression from an all metal fuel grain. A metal fuel grain would act as a high conductivity heat sink, and heat conducted into the fuel could cause more metal to melt than is desired. This could be a particular problem for an aluminum-magnesium alloy fuel which has a lower melting point than pure aluminum. To deal with the problem of the metal's high thermal conductivity, Sparks ${ }^{5}$ suggested using a fuel formed by holding either aluminum powder or fine wire together with a low thermal conductivity binder. The main disadvantage of using a binder is that it would have to be brought from Earth. Another option to prevent premature melting of the aluminum is to actively cool it with the liquid oxygen. The concept considered by Brower et al. ${ }^{6}$ was based on this premiss. However, their analysis was not able to establish a design with sufficient cooling provided by the LOX.

Another disadvantage of the hybrid engine concept is that a hybrid depends on regression of the grain surface to provide fuel to the engine, and large fuel drops $(>50 \mu \mathrm{m})$, like those formed in a solid propellant engine, may be expected. These could lead to large aluminum combustion related losses. Other disadvantages would include increased maintenance requirements (to load a new fuel grain into the thrust chamber) and less flexibility for engine out operation than with the other concepts (because the fuel is stored within each thrust chamber).

\section{Monopropellant Engine}

There are many advantages to combining powdered metal with liquid oxygen, Since the monopropellant could be treated like a liquid, a single pump or positive expulsion feed system could deliver all of the propellant. This could be a simple system, though the feed system would be a new technology. Further, alloys with magnesium could be used, although they may be more sensitive to ignition sources than pure aluminum. If the monopropellant is atomized into small $(20 \mu \mathrm{m})$ drops, even smaller drops of metal will remain after the oxygen vaporizes. Thus, the two-phase flow losses could be reduced with this concept. Another advantage would be that throat erosion and cooling could be handled by a sacrificial insert. 
Other advantages of this concept include the ability to throttle, stop, and restart the engine. Maintenance for this engine concept should be minimal as well, though the slurry combination may erode some feed system components after extended use.

While the monopropellant has many advantages, there are some significant disadvantages. The propellant itself may not be intrinsically safe. Although small scale tests have worked with aluminum/LOX, aluminum-magnesium/LOX, and silicon/LOX monopropellants safely, large scale tests and feed system related tests (e.g. water hammer and pipe flow) have not been performed. If the monopropellant were to ignite in the feed system, the result would be catastrophic. Engine cooling is another challenging design issue. The chamber cooling analysis indicated that even when all of the LOX is available for cooling an aluminum/oxygen engine, a high-pressure feed system is needed. With the monopropellant, only a fraction of the LOX could be available for cooling. Two cooling options remain: either operate at a higher mixture ratio, or use the monopropellant itself as the coolant. The former option would result in lower specific impulse performance for the engine, and the latter option, in addition to raising safety issues about warming the monopropellant, requires flowing a slurry through coolant passages which could plug.

\section{Pneumatic Feed System Engine}

The pneumatic feed system engine concept has several advantages. An alloy of aluminum/magnesium would work equally as well in the feed system as pure aluminum. Another advantage is that small fuel drops could be formed by injecting a fine powder, although particles smaller than $10 \mu \mathrm{m}$ tend to stick together and are difficult to transport pneumatically. The capability to use alloy fuels and to inject fine powdered fuels should reduce the aluminum combustion related losses of the propellant. As with the other engine concepts, throat inserts would be an acceptable solution for throat cooling and erosion protection for this concept. Of course, the other issues of throat inserts must be resolved before the technology can be used. The required engine throttling, stops, and restarts would also be possible with this concept, but a feed line purge would be necessary to clean the lines and injectors of powder after stopping the engine.

There are some disadvantages to using a pneumatic feed system engine concept. For example, though the cooling analysis indicated high oxygen pressures would be necessary, the pneumatic fuel feed is not compatible with pumping since the particles would erode pump blades, and high fuel pressures cannot be obtained. Thus, it would not be possible to take advantage of the high oxygen pressure by operating at a high chamber pressure. Another disadvantage of this concept is that erosion of the feed lines may limit their life. Line erosion increases with flow velocity, and the mission throttling requirement would force a wide range of flow velocities. If eroded feed system components must be replaced, maintenance for this concept could become excessive. 


\section{Concluding Remarks}

Three key issues associated with designing an efficient aluminum/oxygen propellant rocket engine have been considered, and a brief analysis of each issue was performed to evaluate its significance. These analyses were based on information drawn from studies of aluminized solid propellants, which limited their applicability in some respects to aluminum/oxygen propellant engines. Despite these limitations, the results of the analyses do indicate several potential solutions to design issues. The impact of these issues on four potential engine concepts was considered.

It was shown that the effects of aluminum combustion may cause a reduction in performance as great as $10 \%$ of the ideal specific impulse. Since this performance reduction is largely a function of the mass fraction of condensed material in the exhaust, higher efficiencies were obtained at higher mixture ratios, but these higher efficiencies only translated into higher performance up to a mixture ratio of 3.3. Consideration of the aluminum combustion mechanism in solid propellant engines led to two potential methods for improving the performance of an aluminum/oxygen engine. The fuel could be provided in small droplets or use of an alloy of aluminum with a faster burning, lower melting point metal could be considered.

The use of sacrificial carbon-carbon throat inserts for cooling and erosion protection of aluminum/oxygen engines was considered. The mass of such inserts for a lunar ascent/descent vehicle propulsion system is small and should not affect overall mission performance. Other issues associated with using ablative inserts must still be evaluated.

The analysis of engine cooling with liquid oxygen showed that the liquid oxygen cooling of a $66,700 \mathrm{~N}$ thrust engine at a mixture ratio of 3.0 is feasible. However, the temperature increase of the coolant would require a moderate to high coolant operating pressure to avoid a phase change. Alternatively, it may be desirable to operate the engine at a high mixture ratio so that more LOX is available for cooling. This limitation is a prime design requirement which must be considered when selecting an engine concept.

While these analyses were not intended to quantitatively rank the four engine concepts presented, a qualitative evaluation of the concepts indicated the strengths and weaknesses of each. The engine concepts show promise for resolving the issues of using aluminum/oxygen propellant such that the benefits of in situ propellants can be reaped by future exploration missions.

\section{References}

1. Heiken, G., Vaniman, D., and French, B., Lunar Source Book: A Users Guide to the Moon, Cambridge Univ. Press, Cambridge, U.K., 1991. 
2. Teeter, R.R., and Crabb, T.M., "Lunar Surface Base Propulsion System Study," NASA-CR-171982, vol. 1, February, 1987.

3. Wickman, J.H., Oberth, A.E., and Mockenhaupt, J.D., "Lunar Base Spacecraft Propulsion with Lunar Propellants," Paper AIAA-86-1763, AIAA/ASME/SAE/ASEE 22nd Joint Propulsion Conference, June 16-18, 1986.

4. Stancati, M.L., Jacobs, M.K., Cole, K.J., and Collins, J.T., "In Situ Propellant Production: Alternatives for Mars Exploration," NASA CR 187192, October, 1991.

5. Sparks, D.R., "Hybrid Rocket Propellants From Lunar Material", Acta Astronautica, vol. 17, No. 10, pp. 1093-1097, 1988.

6. Brower, D. Adams, Kelly, T., Ewing, C., and Wiersema, T., "Conceptual Design of Hybrid Rocket Engine Utilizing Lunar-Derived Propellant," Paper AIAA-90-2114, AIAA/SAE/ASME/ASEE 26th Joint Propulsion Conference, July 16-18, 1990.

7. Woods, S.S., "Liquid-Oxygen/Metal Gelled Propellants Hazards Analysis (Phase I)," NASA TR-625-001, NASA JSC White Sands Test Facility, Las Cruces, NM, January, 1990.

8. Rathgeber, K., and Beeson, H., "LOX/Metal Gel Mechanical Impact Test Special Test Data Report," WSTF No. 90-24223-28,90-24490-91, January, 1991.

9. Wickman, J., "Liquid Oxygen/Metal Gelled Monopropellants," NASA-CR-187193, October, 1991.

10. Linne, D.L., and Meyer, M.L., "Technical Prospects for Utilizing Extraterrestrial Propellants for Space Exploration," NASA TM 105263, Prepared for the 42nd Congress of the International Astronautical Federation, Montreal, October 5-11, 1991.

11. Loftus, H.J., Montanino, L.N., and Bryndle, R.C., "Powder Rocket Feasibility Evaluation," Paper AIAA 72-1162, AIAA/SAE 8th Joint Propulsion Specialist Conference, New Orleans, November 29 - December 1, 1972.

12. Tamura, K., Kohno, M., and Akiba, R., "A Feasibility Study of a Jet Pump for Powder Rockets," Proceedings of the 11th International Symposium on Space Technology and Science, pp. 117-122, June 30 - July 4, 1975.

13. Hoglund, R.F., "Recent Advances in Gas-Particle Nozzle Flows," American Rocket Society Journal, vol. 32, pp. 662-671, 1962.

14. Sarner, S.F., Propellant Chemistry, Reinhold Publishing Corporation, New York, 1966. 
15. Gordon, S., and McBride, B.J., "Computer Program for Calculation of Complex Chemical Equilibrium Compositions, Rocket Performance, Incident and Reflected Shocks, and Chapman-Jouguet Detonations," NASA SP-273, March, 1976.

16. Price, E.W., "Combustion of Metalized Propellants, " in Fundamentals of Solid Propellant Combustion, Edited by Kuo, K.K. and Summerfield, M., Progress in Astronautics and Aeronautics, vol. 90,American Institute of Aeronautics and Astronautics, Inc., 1984.

17. Shorr, M., and Zaehringer, A.J., eds., "Solid Rocket Technology," John Wiley and Sons, New York, 1967.

18. Bartlett, R.W., Ong, J.N., Jr., Fassell, W.M., Jr., and Papp, C.A., "Estimating Aluminum Particle Combustion Kinetics," Combustion and Flame, vol. 7, p. $227-$ 234, September 1963.

19. Razdobreev, A.A., Skorik, A.I., and Frolov, Y.V., "Ignition and Combustion Mechanism in Aluminum Particles," Fizika Goreniya i Vzryva, vol. 12, no. 2, March-April, 1976.

20. Gordon, D.A., "Combustion Characteristics of Metal Particles," in Solid Propellant Rocket Research, Progress in Astronautics and Rocketry, Volume 1, Editied by M. Summerfield, New York, Academic Press Inc., 1960.

21. Mayberry, J.L., Kordig, J.W., Zeamer, R.J., and Browning, S.C., "Correlation of Graphite Nozzle Throat Erosion in Solid-Rocket Motors," AIAA Journal, vol. 6, no. 11, pp. 2222-2224, November, 1968.

22. Rousar, D., and Miller, F., "Cooling with Supercritical Oxygen," Paper AIAA-751248, AIAA/SAE 11th Propulsion Conference, Anaheim, California, September 29 October 1, 1975.

23. Dederra, H., and Kirner, E., "High Pressure Rocket Engine Liquid Oxygen Technology," Paper IAF-76-174, XXVII Congress, International Astronautics Federation, Anaheim, California, October, 1976.

24. Armstrong, E.S., "Cooling of In Situ Propellant Rocket Engines for Mars Missions," NASA TM 103729, January, 1991.

25. Price, H.G., "Cooling of High-Pressure Rocket Thrust Chambers with Liquid Oxygen," Journal of Spacecraft and Rockets, vol. 18, no. 4, pp. 338-343, JulyAugust 1981. 
26. Baumeister, T., Avallone, E.A., and Baumeister, T. III, eds., "Mark's Standard Handbook for Mechanical Engineers," Eighth Edition, McGraw-Hill Book Company, 1978.

27. Sonntag, R.E., and Van Wylen, G.J., Introduction to Thermodynamics, Classical and Statistical, $2^{\text {od }}$ Edition, John Wiley and Sons, New York, 1982.

28. Mondolfo, L.F., Metallography of Aluminum Alloys, John Wiley \& Sons, Inc., New York, 1943. 
Table 1. Elemental Breakdown of the Lunar Regolith

\begin{tabular}{||l|c|}
\hline \multicolumn{1}{|c|}{ Element } & Weight Percent \\
\hline \hline Oxygen, $\mathrm{O}_{2}$ & 42 \\
\hline Silicon, $\mathrm{Si}$ & 20 \\
\hline Aluminum, $\mathrm{Al}$ & 9 \\
\hline Iron, $\mathrm{Fe}$ & 9 \\
\hline Calcium, $\mathrm{Ca}$ & 8 \\
\hline Magnesium, $\mathrm{Mg}$ & 4 \\
\hline Titanium, $\mathrm{Ti}$ & 3 \\
\hline Other $(\mathrm{P}, \mathrm{S}, \mathrm{Na}$, etc.) & 5 \\
\hline
\end{tabular}

Table 2. Lunar Propellant Options

\begin{tabular}{|c|c|c|c|c|}
\hline Propellant & $\begin{array}{c}\text { Mixture } \\
\text { Ratio(O:F) }\end{array}$ & $\begin{array}{c}\mathrm{I}_{\mathrm{vac}}{ }^{* *} \\
\text { (seconds) }\end{array}$ & $\begin{array}{c}\text { Bulk Density } \\
\left(\mathrm{kg} / \mathrm{m}^{3}\right)\end{array}$ & $\begin{array}{c}\text { Density-Impulse } \\
\left(\mathrm{kg}-\mathrm{s} / \mathrm{m}^{3}\right)\end{array}$ \\
\hline \hline $\mathrm{Al} / \mathrm{O}_{2}$ & 2.5 & 290.4 & 1.375 & 399.3 \\
\hline $\mathrm{Si} / \mathrm{O}_{2}$ & 3.0 & 283.2 & 1.316 & 372.7 \\
\hline $\mathrm{Mg} / \mathrm{O}_{2}$ & 2.5 & 278.9 & 1.272 & 354.8 \\
\hline
\end{tabular}

- Mixture Ratio Selected at Peak Specific Impulse Performance.

- Ideal Performance with Chamber Pressure $=2.07 \times 10^{6} \mathrm{~N} / \mathrm{m}^{2}$ and Nozzle Expansion Ratio $=100$. 
Table 3. Comparison of Aluminum/Oxygen Engine Concepts

\begin{tabular}{|c|c|c|c|c|c|c|c|c|}
\hline \multirow[t]{2}{*}{$\begin{array}{l}\text { Requirement } \\
\text { or Isaue }\end{array}$} & \multicolumn{2}{|c|}{$\begin{array}{c}\text { Aluminum Combustion } \\
\text { Issue: }\end{array}$} & \multirow{2}{*}{$\begin{array}{l}\text { Throat } \\
\text { Erosion' } \\
\text { Cooling }\end{array}$} & \multirow{2}{*}{$\begin{array}{l}\text { Chamber } \\
\text { Cooling }\end{array}$} & \multirow{2}{*}{$\begin{array}{l}\text { Throuling, } \\
\text { Engine Out, } \\
\text { ond Reatart } \\
\text { Capabitity }\end{array}$} & \multirow{2}{*}{$\begin{array}{l}\text { Maintemancel } \\
\text { Reusability }\end{array}$} & \multirow[t]{2}{*}{ Safety } & \multirow{2}{*}{$\begin{array}{l}\text { Other } \\
\text { Issues }\end{array}$} \\
\hline & $\begin{array}{l}\text { Alloy } \\
\text { Use }\end{array}$ & $\begin{array}{l}\text { Fuel } \\
\text { Drop } \\
\text { Size }\end{array}$ & & & & & & \\
\hline $\begin{array}{l}\text { Liquid Metal } \\
\text { Injection }\end{array}$ & + & + & 0 & 0 & 0 & 0 & 0 & - \\
\hline Hybrid & 0 & - & $0 /-$ & 0 & +10 & - & + & 0 \\
\hline $\begin{array}{l}\text { A/LOX } \\
\text { Monopropellant }\end{array}$ & + & + & 0 & - & + & +10 & 0 & 0 \\
\hline $\begin{array}{l}\text { Pneumatic } \\
\text { Powder-Fuel } \\
\text { Feed System }\end{array}$ & + & + & 0 & $0 /-$ & + & 0 & +10 & 0 \\
\hline
\end{tabular}

+ Good Capability

o Problems Must Still Be Resolved

- Significant Problems Exist

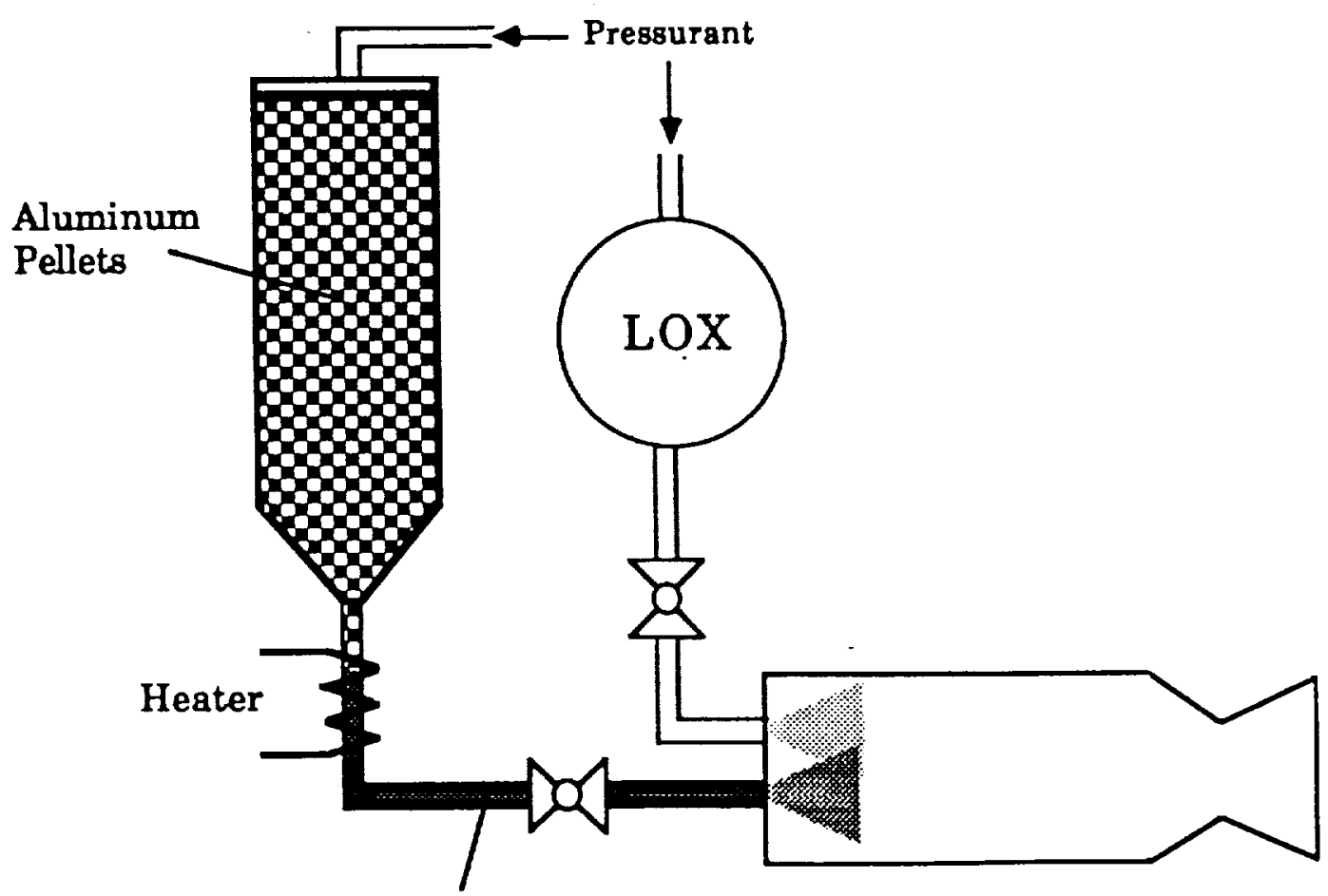

Liquid Aluminum

Figure 1. Liquid Metal Injection Engine Concept 


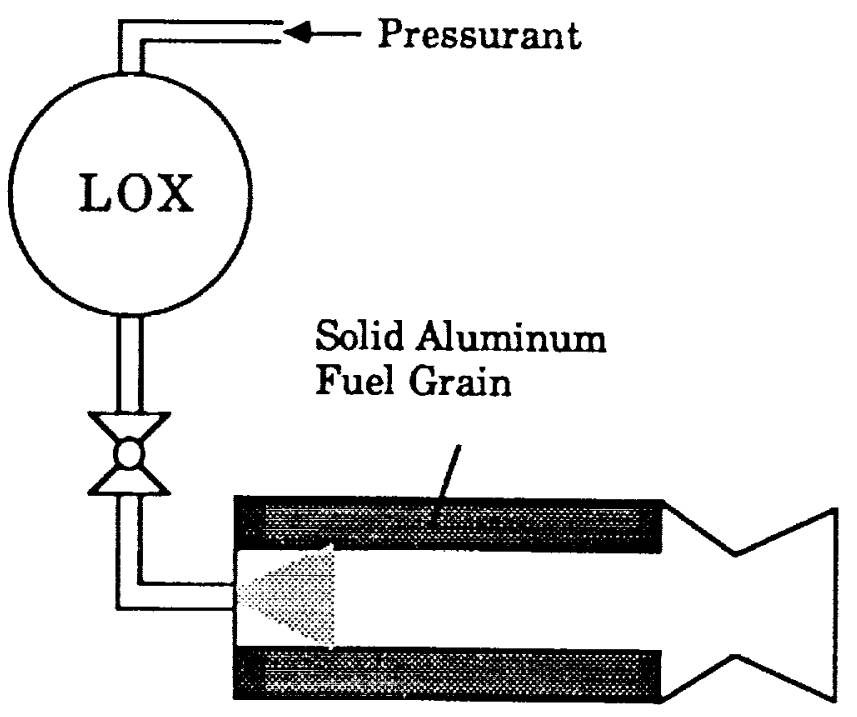

Figure 2. Hybrid Engine Concept

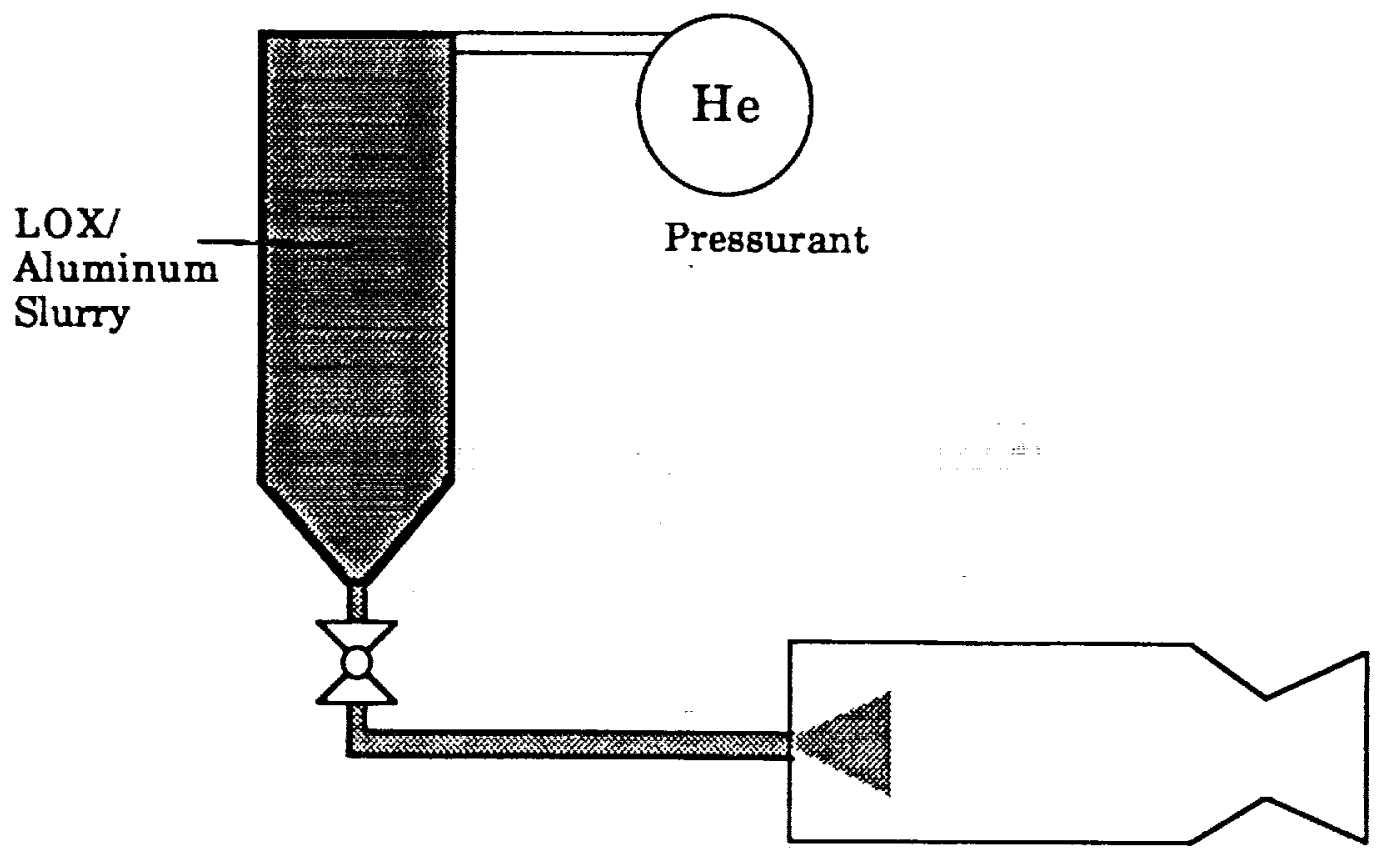

Figure 3. LOX/Aluminum Slurry Engine Concept 


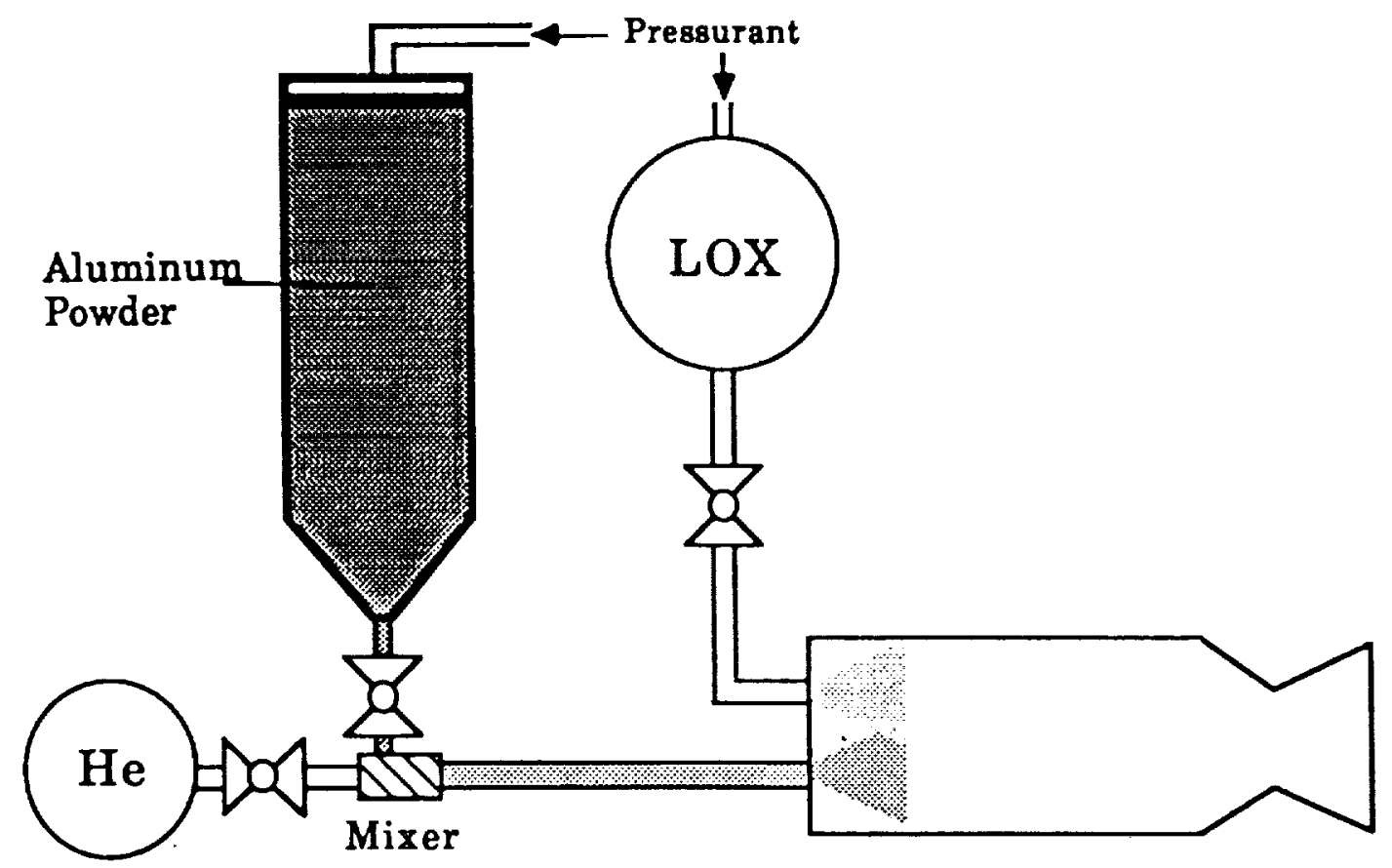

Carrier Gas

Figure 4. Pneumatically Transported Aluminum Powder Engine Concept

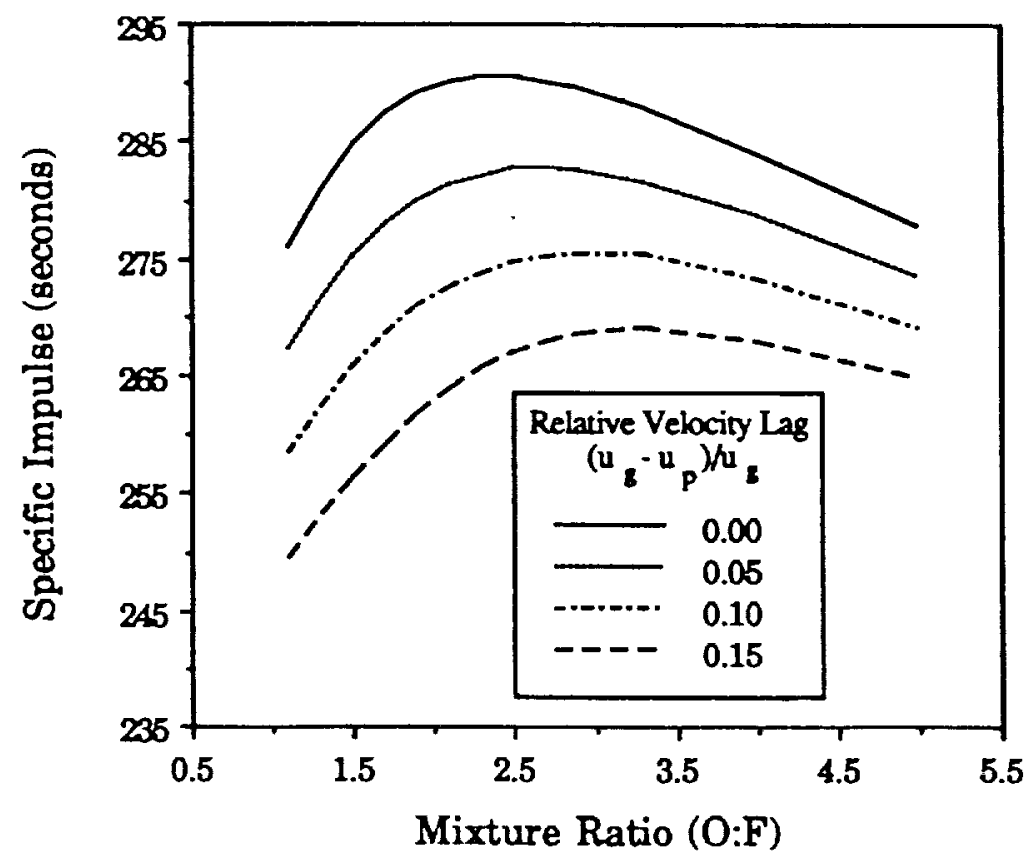

Figure 5. Effect of particle velocity lag on an aluminum/oxygen rocket 


\begin{tabular}{|c|c|c|c|}
\hline \multicolumn{3}{|c|}{ REPORT DOCUMENTATION PAGE } & $\begin{array}{l}\text { Form Approved } \\
\text { OMB No. } 0704-0188\end{array}$ \\
\hline \multicolumn{4}{|c|}{$\begin{array}{l}\text { Public reporting burden for this collection of information is estimated to average } 1 \text { hour per response, including the fime for reviewing instructions, searching existing data sources, } \\
\text { gathering and maintaining the data needed, and completing and reviewing the collection of information. Send comments regarding this burden estimate or any other aspect of this } \\
\text { collection of information, including suggestions for reducing this burden, to Washington Headquaners Senvices, Directorate for intormation Operations and Reports, } 215 \text { Jefferson } \\
\text { Davis Highway, Suite 1204, Arlington, VA 22202-4302, and to the Office of Management and Budget, Paperwork Reduction Project (0704-0188), Washington, DC 20503. }\end{array}$} \\
\hline 1. AGENCY USE ONLY (Leave blank) & $\begin{array}{r}\text { 2. REPORT DATE } \\
1992 \\
\end{array}$ & \multicolumn{2}{|c|}{$\begin{array}{l}\text { 3. REPORT TYPE AND DATES COVERED } \\
\text { Technical Memorandum }\end{array}$} \\
\hline \multicolumn{3}{|c|}{$\begin{array}{l}\text { 4. TITLE AND SUBTITLE } \\
\text { Design Issues for Lunar In Situ Aluminum/Oxygen } \\
\text { Propellant Rocket Engines }\end{array}$} & 5. FUNDING NUMBERS \\
\hline \multicolumn{3}{|l|}{$\begin{array}{l}\text { 6. AUTHOR(S) } \\
\text { Michael L. Meyer }\end{array}$} & WU - 506-42 \\
\hline \multicolumn{3}{|c|}{$\begin{array}{l}\text { 7. PERFORMING ORGANIZATION NAME(S) AND ADDRESS(ES) } \\
\text { National Aeronautics and Space Administration } \\
\text { Lewis Research Center } \\
\text { Cleveland, Ohio } 44135-3191\end{array}$} & $\begin{array}{l}\text { 8. PERFORMING ORGANIZATION } \\
\text { REPORT NUMBER }\end{array}$ \\
\hline \multicolumn{3}{|c|}{$\begin{array}{l}\text { National Aeronautics and Space Administration } \\
\text { Washington, D.C. } 20546-0001\end{array}$} & $\begin{array}{l}\text { NASA TM }-105433 \\
\text { AIAA }-92-1185\end{array}$ \\
\hline \multicolumn{4}{|c|}{$\begin{array}{l}\text { Prepared for the } 1992 \text { Aerospace Design Conference sponsored by the American Institute of Aeronautics and } \\
\text { Astronautics, Irvine, California, February 3-6, 1992. Responsible person, Michael L. Meyer, (216) 977-7492. }\end{array}$} \\
\hline $\begin{array}{l}\text { 12a. DISTRIBUTION/AVAILABILIT } \\
\text { Unclassified - Unlimited } \\
\text { Subject Category } 20\end{array}$ & STATEMENT & & 12b. DISTRIBUTION CODE \\
\hline \multicolumn{4}{|c|}{$\begin{array}{l}\text { 13. ABSTRACT (Maximum } 200 \text { words) } \\
\text { Design issues for lunar ascent/descent rocket engines fueled by aluminum/oxygen propellant produced in situ at the } \\
\text { lunar surface were evaluated. Key issues are discussed which impact the design of these rockets: aluminum } \\
\text { combustion, throat erosion, and thrust chamber cooling. Four engine concepts are presented, and the impact of } \\
\text { combustion performance, throat erosion and thrust chamber cooling on overall engine design are discussed. The } \\
\text { advantages and disadvantages of each engine concept are presented. }\end{array}$} \\
\hline \multicolumn{3}{|c|}{$\begin{array}{l}\text { 14. SUBJECT TERMS } \\
\text { In situ propellants; Aluminum; Rocket engine design; Liquid/oxygen cooling }\end{array}$} & $\begin{array}{l}\text { 15. NUMBER OF PAGES } \\
20 \\
\text { 16. PRICE CODE }\end{array}$ \\
\hline $\begin{array}{l}\text { 17. SECURITY CLASSIFICATION } \\
\text { OF REPORT } \\
\text { Unclassified }\end{array}$ & $\begin{array}{l}\text { 18. SECURITY CLASSIFICATION } \\
\text { OF THIS PAGE } \\
\text { Unclassificd }\end{array}$ & $\begin{array}{l}\text { 19. SECURTY CLASSIFICATION } \\
\text { OF ABSTRACT } \\
\text { Unclassified }\end{array}$ & 20. LIMITATION OF ABSTRACT \\
\hline NSN 7540-01-280-5500 & & & $\begin{array}{l}\text { andard Form } 298 \text { (Rev. 2-89) } \\
\text { scribed by ANSI Std. Z39-18 } \\
3-102\end{array}$ \\
\hline
\end{tabular}

